\title{
Radiation Dose-Response Relationship for Risk of Coronary Heart Disease in Survivors of Hodgkin Lymphoma
}

Frederika A. van Nimwegen, Michael Schaapveld, David J. Cutter, Cècile P.M. Janus, Augustinus D.G. Krol, Michael Hauptmann, Karen Kooijman, Judith Roesink, Richard van der Maazen, Sarah C. Darby, Berthe M.P. Aleman, and Flora E. van Leeuwen

See accompanying editorial on page 208

Frederika A. van Nimwegen, Michael Schaapveld, Michael Hauptmann, Karen Kooijman, Berthe M.P. Aleman, and Flora E. van Leeuwen, Netherlands Cancer Institute, Amsterdam; Michael Schaapveld, Netherlands Comprehensive Cancer Organization; Judith Roesink, University Medical Center Utrecht, Utrecht; Cècile P.M. Janus, Erasmus MC Cancer Institute, Rotterdam; Augustinus D.G. Krol, Leiden University Medical Center, Leiden; Richard van der Maazen, Radboud University Medical Center, Nijmegen, Netherlands; David J. Cutter, and Sarah C. Darby, University of Oxford; and David J. Cutter, Oxford University Hospitals NHS Trust, Oxford, United Kingdom.

Published online ahead of print at www.jco.org on November 16, 2015.

Supported by Grant No. NKI 2010-4720 from the Dutch Cancer Society and by core funding to the Oxford University Clinical Trial Services Unit.

Berthe M.P. Aleman and Flora E. van Leeuwen are joint last authors.

Presented in part at the European Symposium of Late Effects in Childhood Cancer Survivors, Amsterdam, Netherlands, September 30, 2011.

Presented at the International Conference on Late Effects in Childhood Cancer Survivors, Arlington, VA, June 12, 2015. Presented at the 13th International Conference on Malignant Lymphoma, Lugano, Switzerland, June 17, 2015.

Authors' disclosures of potential conflicts of interest are found in the article online at www.jco.org. Author contributions are

found at the end of this article.

Corresponding author: Flora E. van Leeuwen, PhD, Department of

Epidemiology and Biostatistics, Netherlands Cancer Institute,

Plesmanlaan 121, 1066 CX Amsterdam, Netherlands; e-mail: f.v.leeuwen@nki.nl.

(c) 2015 by American Society of Clinical Oncology

0732-183X/16/3403w-235w/\$20.00 DOI: $10.1200 / J C O .2015 .63 .4444$

\section{$\begin{array}{llllllll}\text { A } & \text { B } & \mathbf{S} & \mathbf{T} & \mathbf{R} & \mathbf{A} & \mathbf{C} & \mathbf{T}\end{array}$}

\section{Purpose}

Cardiovascular diseases are increasingly recognized as late effects of Hodgkin lymphoma $(\mathrm{HL})$ treatment. The purpose of this study was to identify the risk factors for coronary heart disease (CHD) and to quantify the effects of radiation dose to the heart, chemotherapy, and other cardiovascular risk factors.

\section{Patients and Methods}

We conducted a nested case-control study in a cohort of 2,617 5-year HL survivors, treated between 1965 and 1995. Cases were patients diagnosed with CHD as their first cardiovascular event after HL. Detailed treatment information was collected from medical records of 325 cases and 1,204 matched controls. Radiation charts and simulation radiographs were used to estimate in-field heart volume and mean heart dose (MHD). A risk factor questionnaire was sent to patients still alive.

\section{Results}

The median interval between $\mathrm{HL}$ and $\mathrm{CHD}$ was 19.0 years. Risk of $\mathrm{CHD}$ increased linearly with increasing MHD (excess relative risk [ERR]) per Gray, $7.4 \% ; 95 \% \mathrm{Cl}, 3.3 \%$ to $14.8 \%$ ). This results in a 2.5-fold increased risk of $\mathrm{CHD}$ for patients receiving a MHD of $20 \mathrm{~Gy}$ from mediastinal radiotherapy, compared with patients not treated with mediastinal radiotherapy. ERRs seemed to decrease with each

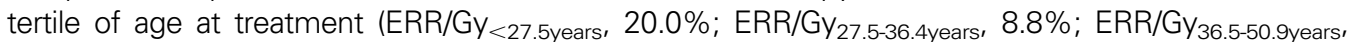
$4.2 \% ; P_{\text {interaction }}=.149$ ). Having $\geq 1$ classic $\mathrm{CHD}$ risk factor (diabetes mellitus, hypertension, or hypercholesterolemia) independently increased $\mathrm{CHD}$ risk (rate ratio, 1.5; 95\% $\mathrm{Cl}, 1.1$ to 2.1 ). A high level of physical activity was associated with decreased CHD risk (rate ratio, $0.5 ; 95 \% \mathrm{Cl}, 0.3$ to 0.8 ).

\section{Conclusion}

The linear radiation dose-response relationship identified can be used to predict CHD risk for future $\mathrm{HL}$ patients and survivors. Appropriate early management of $\mathrm{CHD}$ risk factors and stimulation of physical activity may reduce CHD risk in HL survivors.

\section{J Clin Oncol 34:235-243. (C) 2015 by American Society of Clinical Oncology}

\section{INTRODUCTION}

Hodgkin lymphoma (HL) treatment has improved over recent decades, leading to a 10 -year survival rate of more than $80 \% .{ }^{1}$ However, radiotherapy and chemotherapy are associated with increased cardiovascular morbidity and mortality in long-term survivors. $^{2-7}$ Although radiation doses and target volumes have been reduced over the past decades, mediastinal radiotherapy is still indicated for a substantial proportion of patients, ${ }^{8,9}$ which may result in considerable radiation exposure of the heart.

Few studies have examined the dose-response relationship for cardiac radiation and risk of coronary heart disease (CHD) after radiotherapy. A recent study by Darby et al ${ }^{10}$ showed a linear doseresponse relationship between radiation dose to the heart and CHD risk in breast cancer survivors for a relatively low range of mean heart dose (MHD) (range, 0.03-27.7 Gy; average, $5 \mathrm{~Gy}$ ). The shape of the dose-response relationship has not been studied in HL patients, who generally receive much higher MHDs and are usually younger at diagnosis than breast cancer patients.

Schellong et $\mathrm{al}^{11}$ and Mulrooney et $\mathrm{al}^{12}$ observed an association between cardiovascular diseases and prescribed mediastinal radiation dose and MHD among childhood HL (and other cancer) survivors; however, the shape of the radiation dose-response relationship and excess relative risks (ERRs) were not described. 
In addition to the shape of the dose-response relationship, the roles of established cardiovascular disease risk factors and lifestyle on CHD risk have rarely been studied among HL survivors. ${ }^{4,5,13}$ Therefore, the aim of this study was to assess the shape of the doseresponse curve for cardiac radiation dose and the risk of CHD in adolescent and adult HL survivors and to investigate the role of chemotherapy, lifestyle, and other established cardiovascular disease risk factors.

\section{PATIENTS AND METHODS}

\section{Study Population}

We conducted a nested case-control study in an existing cohort $(\mathrm{N}=$ 2,617) of HL survivors treated in the Netherlands between 1965 and 1995. The cohort was derived from hospital-based cancer registries of four large university hospitals and one cancer center. Details on patient selection and data collection have been published previously. ${ }^{2,7,12,14-17}$ Patients were eligible for this study if (1) they survived $\geq 5$ years after HL diagnosis; (2) they were diagnosed with HL before the age of 51 years; (3) HL was their first primary malignancy, except for nonmelanoma skin cancer or carcinoma in situ of the cervix uteri or the breast; and (4) radiotherapy for HL was the only radiotherapy given to the neck or trunk before the cutoff date, which was defined as the date of CHD for the cases or the date of HL diagnosis plus a time interval equal to the interval from the date of $\mathrm{HL}$ diagnosis to the date of CHD diagnosis of the corresponding case for matched controls.

\section{Cases and Controls}

Cases $(n=325)$ were patients who developed CHD in the form of either symptomatic myocardial infarction or angina pectoris requiring intervention (Common Terminology Criteria for Adverse Events, version 4.0 , grade $\geq 2$; Appendix Text A1, online only) ${ }^{18}$ as their first clinically significant heart disease. Cases were identified from medical records or postal questionnaires completed by their general practitioners. Follow-up was complete up to October 2013. For each case with CHD, we attempted to select four controls from the cohort, individually matched on sex, age at HL diagnosis ( $\leq 1$ year), and date of HL diagnosis ( $\leq 3$ years). Controls had to be free of any cardiac disease grade $\geq 2$ at the cutoff date. In total, 1,204 controls were matched to the cases.

\section{Data Collection}

Detailed information on treatment (including radiation doses and fields and cumulative doses of cytotoxic drugs), medical history, medication use, smoking, and established cardiovascular risk factors at both diagnosis of HL and during follow-up was collected from medical records and radiation charts. In addition, a questionnaire on established cardiovascular risk factors and lifestyle was mailed to all patients still alive in $2013(n=475)$ in three of the five centers (response rate, 70\%). Patients were defined as having a risk factor when the risk factor concerned was diagnosed before CHD or the cutoff date. The ethics review board of the Netherlands Cancer Institute approved this study.

\section{Mean Heart Dose}

The MHD was assessed using the percentage of cardiac volume within field (\%CVWF) method $^{19}$ and converted to equivalent dose in 2-Gy fractions (EQD2) ${ }^{20}$ We recently showed that this method gives reliable MHD estimates for our patient population and compares well with MHD based on computed tomography (CT)-based dosimetry. ${ }^{19}$ We outlined the cardiac contour on the HL simulation radiographs to obtain the \%CVWF. Additional details can be found in Appendix Text A2.

When original radiotherapy charts were unavailable, information about radiotherapy, including dates, anatomic areas, dose, fractionation, and treatment energy, was abstracted from clinical notes. We assigned an average \%CVWF to radiation-treated patients for whom no simulation radiographs were available and an average prescribed dose to patients for whom no prescribed dose was available ( $n=473$, including 105 cases), on the basis of hospital, treatment period, and sex.

\section{Statistical Analysis}

Odds ratios for CHD for different levels of each factor were calculated using conditional logistic regression on sets of individual cases and their matched controls, and were interpreted as rate ratios (RRs). The Wald method was used to calculate $95 \%$ CIs for factors with two levels. The amount of information in each category, including the reference category (so-called floating absolute risks), was used to calculate 95\% CIs for factors with more than two levels. ${ }^{21}$ Multivariable regression was used to assess and control for confounding and to evaluate interactions between radiation dose and other factors.

The dose-response relationship was estimated by modeling the CHD rate as $K_{m}(1+\beta d)$, where $K_{m}$ is a constant specific to each matched set, $\beta$ is the ERR of CHD per unit increase in dose, and $\mathrm{d}$ is the MHD of an individual patient. Nonlinearity was evaluated by including an exponential term: $\mathrm{K}_{\mathrm{m}}[1+\beta \mathrm{d} \cdot \exp (\delta \mathrm{d})]$. Goodness of fit was assessed by likelihood ratio tests. Interactions were evaluated using interaction terms and likelihood ratio tests. Approximate cumulative incidence of $\mathrm{CHD}$ for categories of MHD, with other heart disease or death as a competing risk, was estimated from CHD RRs together with the cumulative risk of CHD for the entire cohort, assuming that the distribution of all individuals in the cohort across the dose categories was equal to that for the control patients.

Significance tests were two-sided and $P \leq 0.05$ was considered to indicate statistical significance. Analyses were performed using STATA statistical software (version 13.0; STATA, College Station, TX) and Epicure (version 1.8; Hiro Soft International Inc, Seattle WA).

\section{RESULTS}

Characteristics of the 325 cases and 1,204 controls are described in Table 1 . The median age of patients was 32.2 years (interquartile range [IQR], 24.4 to 39.6) at the time of HL diagnosis, and the median interval between HL and CHD was 19.0 years (IQR, 13.9 to 25.2). Myocardial infarction was diagnosed in 185 patients; angina pectoris requiring intervention was diagnosed in 140 patients (Appendix Table A1). In total, 169 of 325 cases died, $42.6 \%$ from a cardiovascular disease, after a median follow-up period of 6.0 years after their first CHD (Appendix Table A1). Thirty-one patients died of their first CHD incident within a week.

\section{Radiotherapy}

Ninety-one percent of the cases had received mediastinal radiotherapy, given through parallel-opposed fields, compared with 79\% of the controls (Table 1). Mediastinal radiation therapy was associated with a 2.63-fold increased risk of CHD (95\% CI, 1.74 to 3.99; Table 2). Para-aortic radiotherapy, with or without splenic radiation, was not associated with CHD risk (RR, 0.99; 95\% CI, 0.76 to 1.28 ).

The average MHD was 22.0 Gy for cases and 20.4 Gy for controls (Table 1). A linear radiation dose-response relationship best described the data, and no significant deviation from linearity was observed $\left(P_{\text {exponential-term }}=.356\right)$. The ERR for CHD increased by $7.4 \%$ per Gy (95\% CI, 3.3\% to $14.8 \%$; Fig 1), resulting in a 1.74-fold increased risk at a MHD of $10 \mathrm{~Gy}(95 \% \mathrm{CI}, 1.33$ to 2.48$)$ and a 2.48 -fold increased risk at a MHD of $20 \mathrm{~Gy}$ (95\% CI, 1.66 to 3.96). The approximate 25year cumulative $\mathrm{CHD}$ incidence was $4.1 \%$ for patients with a MHD of 


\begin{tabular}{|c|c|c|c|c|}
\hline Characteristic & No. of Cases* & $\%$ & No. of Controls* & $\%$ \\
\hline Total & 325 & 100 & 1,208 & 100 \\
\hline \multicolumn{5}{|l|}{ Sex } \\
\hline Men & 236 & 72.6 & 889 & 73.9 \\
\hline Women & 89 & 27.4 & 319 & 26.4 \\
\hline Age at diagnosis, years (median, IQR) & 32.3 & 24.5-39.4 & 32.2 & 24.4-39.6 \\
\hline ( & 98 & 30.2 & 370 & 30.6 \\
\hline $26-32$ & 73 & 22.5 & 271 & 22.4 \\
\hline 33-39 & 80 & 24.6 & 292 & 24.2 \\
\hline $40-50$ & 74 & 22.8 & 275 & 22.8 \\
\hline \multicolumn{5}{|l|}{ Year of diagnosis } \\
\hline $1965-1974$ & 116 & 35.7 & 429 & 35.5 \\
\hline 1975-1984 & 124 & 38.2 & 513 & 32.5 \\
\hline 1985-1995 & 85 & 26.2 & 266 & 22.0 \\
\hline Time to IHD/cutoff (median, IQR) & 19.0 & $13.9-25.2$ & 19.2 & $13.9-25.2$ \\
\hline \multicolumn{5}{|l|}{ Smoking } \\
\hline Smoked at $\mathrm{HL}$ diagnosis & 195 & 61.1 & 645 & 55.1 \\
\hline Smoking at end of follow-up & 93 & 31.1 & 321 & 30.0 \\
\hline Ever smoked & 236 & 74.0 & 820 & 69.7 \\
\hline Recent smoker at time of cutoff ( $<5$ years) & 109 & 34.0 & 350 & 29.0 \\
\hline Unknown time of quitting smoking & 77 & 23.7 & 251 & 20.8 \\
\hline \multicolumn{5}{|l|}{ Classic risk factors } \\
\hline Diabetes mellitus diagnosed before $\mathrm{CHD} /$ cutoff date & 11 & 3.4 & 38 & 3.2 \\
\hline Hypercholesterolemia diagnosed before $\mathrm{CHD} /$ cutoff date & 31 & 9.5 & 89 & 7.4 \\
\hline Hypertension diagnosed before $\mathrm{CHD} /$ cutoff date & 54 & 16.6 & 122 & 10.1 \\
\hline Obesity at $\mathrm{HL}$ & 16 & 5.2 & 33 & 3.0 \\
\hline Obesity at end of follow-up (BMI $\left.\geq 30 \mathrm{~kg} / \mathrm{m}^{2}\right)$ & 106 & 36.3 & 288 & 27.3 \\
\hline At least one of the above risk factors & 80 & 24.6 & 213 & 17.6 \\
\hline \multicolumn{5}{|l|}{ Treatment of $\mathrm{HL} \dagger$} \\
\hline Radiotherapy & 315 & 96.9 & 1097 & 90.8 \\
\hline Subdiaphragmatic radiotherapy & 157 & 48.3 & 573 & 47.4 \\
\hline Mediastinal radiotherapy & 296 & 91.1 & 957 & 79.2 \\
\hline Chemotherapy & 200 & 61.5 & 805 & 66.6 \\
\hline Alkylating CT & 167 & 84.3 & 686 & 87.1 \\
\hline Procarbazine & 139 & 42.9 & 614 & 50.9 \\
\hline Vincristine & 135 & 41.7 & 585 & 48.5 \\
\hline Anthracyclines & 68 & 21.0 & 226 & 18.7 \\
\hline Splenectomy & 103 & 32.0 & 384 & 32.5 \\
\hline Prescribed mediastinal dose, Gy (median, IQR)‡ & 33 & 29-37 & 33 & $29-38$ \\
\hline 0 & 29 & 8.9 & 251 & 20.8 \\
\hline $15-24$ & 5 & 1.5 & 28 & 2.3 \\
\hline $25-34$ & 26 & 8.0 & 98 & 8.1 \\
\hline $35-39$ & 156 & 48.0 & 537 & 44.5 \\
\hline $40-45$ & 109 & 33.5 & 294 & 24.3 \\
\hline Mean heart dose, Gy (median, IQR) & 21.7 & 18.4-25.7 & 20.2 & $17.5-24.8$ \\
\hline 0 & 17 & 5.2 & 160 & 13.3 \\
\hline $1-5$ & 12 & 3.7 & 93 & 7.7 \\
\hline $5-14$ & 19 & 5.9 & 80 & 6.6 \\
\hline $15-1 y$ & 71 & 21.8 & 242 & 20.0 \\
\hline $20-24$ & 102 & 31.4 & 332 & 27.5 \\
\hline 25-34 & 99 & 30.5 & 280 & 23.2 \\
\hline $35-45$ & 5 & 1.5 & 21 & 1.7 \\
\hline Percent cardiac contour within field (median, IQR) & 64 & $55-70$ & 66 & $57-71$ \\
\hline \multicolumn{5}{|c|}{$\begin{array}{l}\text { NOTE. All patients were treated with parallel-opposed fields. } \\
\text { Abbreviations: BMI, body mass index; CHD, coronary heart disease; CT, computed tomography; HL, Hodgkin lymphoma; IHD, ischemic heart disease; IQR, interquartile } \\
\text { range. } \\
\text { *Two-hundred fifty-six cases had four controls, } 48 \text { cases had three controls, } 15 \text { cases had two controls, and six cases had only one control. } \\
\text { †Treatment variables are not mutually exclusive. } \\
\text { fPrescribed dose was missing for five cases and } 19 \text { controls, simulation radiographs were missing for } 84 \text { cases and } 271 \text { controls, and both were missing for } 16 \text { cases } \\
\text { and } 78 \text { controls. Imputation was on the basis of hospital, sex, and treatment period. }\end{array}$} \\
\hline
\end{tabular}

0 Gy, 9.4\% for patients with a MHD of 15 to $20 \mathrm{~Gy}$, and $12.6 \%$ for patients with a MHD of $\geq 25 \mathrm{~Gy}$ (Fig 2). Results were similar when we only included patients for whom the MHD was known (Appendix Table A2). Cases had a median \%CVWF of 66\%, compared with $64 \%$ for controls. Variation in \%CVWF was limited, with interquartile ranges of $57 \%$ to $71 \%$ and $55 \%$ to $70 \%$, respectively (Table 1 ).

\section{Other Treatment-Related Risk Factors}

Chemotherapy was not associated with CHD risk (RR, $0.87 ; 95 \% \mathrm{CI}, 0.67$ to 1.13 ), nor were anthracycline-containing chemotherapy (RR, $1.11,95 \% \mathrm{CI}, 0.76$ to 1.62 ) or vincristinecontaining chemotherapy (RR, $0.86 ; 95 \% \mathrm{CI}, 0.66$ to 1.13 ), after accounting for mediastinal radiotherapy. Splenectomy also 


\begin{tabular}{|c|c|c|c|c|c|c|c|c|}
\hline \multirow[b]{2}{*}{ Treatment Factor } & \multirow{2}{*}{$\begin{array}{c}\text { No. of Cases } \\
(n=325)\end{array}$} & \multirow{2}{*}{$\begin{array}{l}\text { No. of Controls } \\
(n=1,204)\end{array}$} & \multicolumn{2}{|r|}{ Crude } & \multirow[b]{2}{*}{$P$} & \multicolumn{2}{|c|}{ Adjusted* } & \multirow[b]{2}{*}{$P$} \\
\hline & & & $\mathrm{RR}$ & $95 \% \mathrm{Cl}$ & & $\mathrm{RR}$ & $95 \% \mathrm{Cl}$ & \\
\hline \multicolumn{9}{|l|}{ Radiotherapy } \\
\hline No & 10 & 111 & 1 & ref & & 1 & ref & \\
\hline Yes & 315 & 1093 & 3.16 & 1.63 to 6.14 & .001 & 2.99 & 1.52 to 5.85 & .001 \\
\hline \multicolumn{9}{|l|}{ Mediastinal radiotherapy } \\
\hline No & 29 & 251 & 1 & ref & & 1 & ref & \\
\hline Yes & 296 & 953 & 2.71 & 1.79 to 4.08 & $<.001$ & 2.63 & 1.74 to 3.99 & $<.001$ \\
\hline \multicolumn{9}{|l|}{ Para-aortic radiotherapy } \\
\hline No & 168 & 633 & 1 & ref & & 1 & ref & \\
\hline Yes & 157 & 571 & 1.05 & 0.81 to 1.35 & 0.712 & .99 & 0.76 to 1.28 & .927 \\
\hline \multicolumn{9}{|l|}{ Splenic radiotherapy } \\
\hline No & 229 & 878 & 1 & ref & & 1 & ref & \\
\hline Yes & 96 & 326 & 1.13 & 0.86 to 1.50 & .372 & 1.07 & 0.80 to 1.42 & .656 \\
\hline \multicolumn{9}{|l|}{ Prescribed mediastinal dose, Gy } \\
\hline 0 (no mediastinal radiotherapy) & 29 & 251 & 1.00 & 0.68 to 1.48 & & 1.00 & 0.67 to 1.48 & \\
\hline $15-24$ & 5 & 28 & 1.49 & 0.57 to 3.89 & & 1.51 & 0.58 to 3.96 & \\
\hline 25-34 & 26 & 97 & 2.31 & 1.50 to 3.57 & & 2.30 & 1.49 to 3.56 & \\
\hline $35-39$ & 156 & 535 & 2.56 & 2.12 to 3.08 & & 2.52 & 2.10 to 3.03 & \\
\hline $40-45$ & 109 & 293 & 3.12 & 2.50 to 3.90 & $<.001 \dagger$ & 3.03 & 2.41 to 3.82 & $<.001 \dagger$ \\
\hline \multicolumn{9}{|l|}{ Mean heart dose, Gy } \\
\hline 0 & 17 & 160 & 1.00 & 0.60 to 1.66 & & 1.00 & 0.60 to 1.67 & \\
\hline $1-5$ & 12 & 93 & 1.19 & 0.65 to 2.19 & & 1.14 & 0.62 to 2.10 & \\
\hline $5-14$ & 19 & 80 & 2.16 & 1.30 to 3.60 & & 2.14 & 1.28 to 3.58 & \\
\hline $15-19$ & 71 & 239 & 2.83 & 2.16 to 3.71 & & 2.76 & 2.10 to 3.59 & \\
\hline $20-24$ & 102 & 332 & 2.90 & 2.32 to 3.63 & & 2.79 & 2.23 to 3.49 & \\
\hline $25-34$ & 99 & 279 & 3.35 & 2.64 to 4.26 & & 3.21 & 2.52 to 4.09 & \\
\hline $35-45$ & 5 & 21 & 2.62 & 0.99 to 6.90 & $<.001 \dagger$ & 2.54 & 0.96 to 6.69 & $<.001 \dagger$ \\
\hline \multicolumn{9}{|l|}{ Chemotherapy } \\
\hline No & 125 & 402 & 1.00 & ref & & 1 & ref & \\
\hline Yes & 200 & 802 & 0.79 & 0.61 to 1.02 & .069 & 0.87 & 0.67 to 1.13 & .298 \\
\hline \multicolumn{9}{|l|}{ Alkylating chemotherapy } \\
\hline No & 159 & 532 & 1 & ref & & 1 & ref & \\
\hline Yes & 166 & 673 & 0.80 & 0.62 to 1.04 & .101 & 0.92 & 0.70 to 1.20 & .519 \\
\hline \multicolumn{9}{|l|}{ Procarbazine } \\
\hline No & 185 & 591 & 1 & ref & & 1 & ref & \\
\hline Yes & 139 & 612 & 0.70 & 0.54 to 0.91 & .008 & 0.82 & 0.63 to 1.07 & .148 \\
\hline \multicolumn{9}{|l|}{ Vincristine } \\
\hline No & 189 & 620 & 1 & ref & & 1 & ref & \\
\hline Yes & 165 & 583 & 0.73 & 0.56 to 0.95 & .020 & 0.86 & 0.66 to 1.13 & .294 \\
\hline \multicolumn{9}{|l|}{ Anthracyclines } \\
\hline No & 256 & 978 & 1 & ref & & 1 & ref & \\
\hline Yes & 68 & 224 & 1.08 & 0.75 to 1.57 & .670 & 1.11 & 0.76 to 1.62 & .593 \\
\hline \multicolumn{9}{|l|}{ Splenectomy $¥$} \\
\hline No & 219 & 794 & 1 & ref & & 1 & ref & \\
\hline Yes & 103 & 384 & 1.00 & 0.75 to 1.33 & .990 & 0.91 & 0.68 to 1.22 & .521 \\
\hline \multicolumn{9}{|c|}{$\begin{array}{l}\text { NOTE. All patients were treated with parallel-opposed field. Boldface indicates statistically significant RRs. } \\
\text { Abbreviations: ref, reference category; RR, rate ratio. } \\
\text { *Radiation-related factors are adjusted for any chemotherapy. Chemotherapy factors are adjusted for mediastinal radiotherapy. Splenectomy was adjusted for } \\
\text { mediastinal radiotherapy and any chemotherapy. } \\
+P \text { for trend. } \\
\text { †Total numbers of cases and controls may vary because of missing values or inclusion of only patients treated with mediastinal radiotherapy. }\end{array}$} \\
\hline
\end{tabular}

did not affect CHD risk (RR, 0.91; 95\% CI, 0.68 to 1.22 ; Table 2).

\section{Patient-Related Risk Factors}

Twenty-five percent of cases had at least one classic cardiovascular risk factor (diabetes mellitus, hypercholesterolemia, or hypertension) diagnosed before the diagnosis of CHD (Table 1). Only hypertension (RR, $1.85 ; 95 \% \mathrm{CI}, 1.28$ to 2.66 ) and the presence of at least one risk factor (RR, 1.59; 95\% CI, 1.17 to 2.19) were associated with an increased risk of CHD (Table 3 ). When risk factors were taken into account in a less conservative manner, that is, by also including risk factors that were diagnosed around the time of CHD diagnosis or cutoff date, not only hypertension but also diabetes mellitus and hypercholesterolemia were associated with a significantly increased risk of developing CHD (Appendix Table A3). Obesity at the time of CHD diagnosis or the cutoff date was associated with an increased risk of CHD as well (RR, 1.64; $95 \% \mathrm{CI}, 1.24$ to 2.16 ). Whereas ever smoking was not associated with CHD risk, smoking within 5 years before a diagnosis of CHD or the cutoff date was associated with an increased risk of $\mathrm{CHD}$ (RR, 1.56; 95\% CI, 1.13 to 2.15; Table 3). Patients with a high level of physical activity at the time of the follow-up questionnaire $(>3$ 


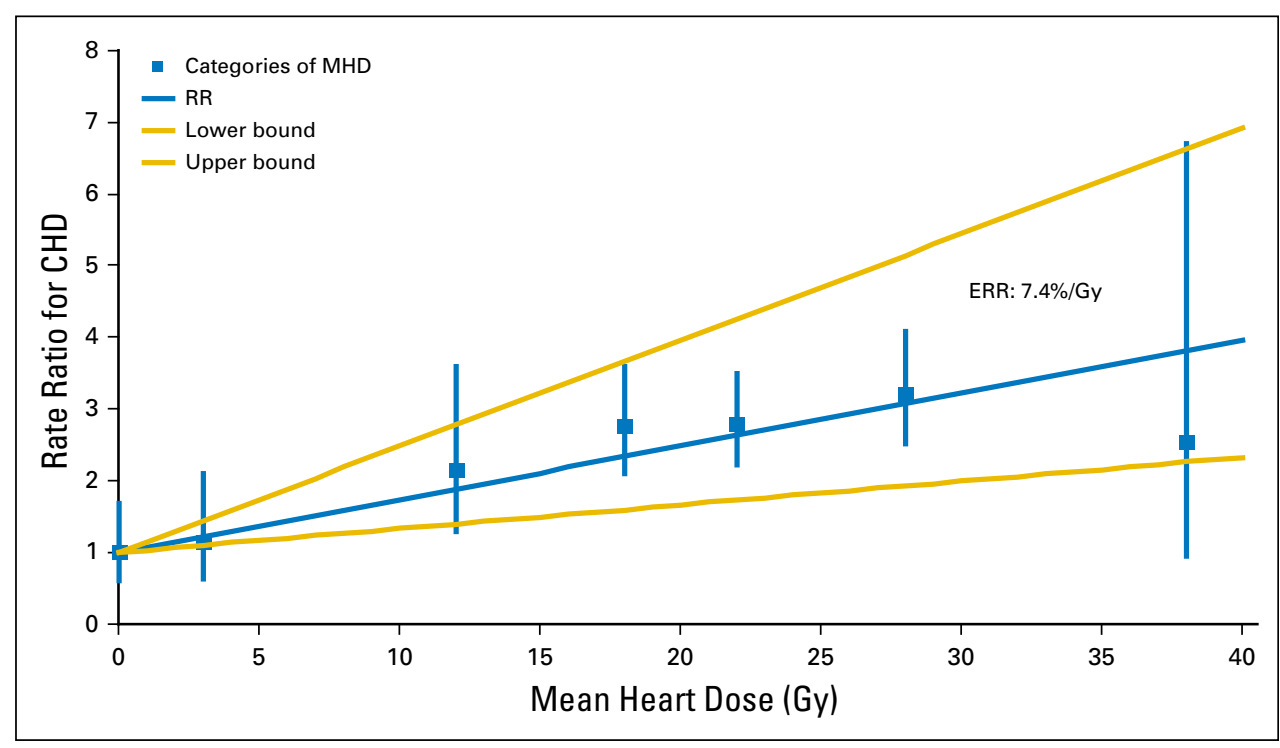

Fig 1. Dose-response curve for mean heart dose (MHD) and coronary heart disease (CHD) risk. Rate ratios (RR) for CHD by estimated MHD (Gy) are compared with no radiation exposure. RR are calculated conditionally on matched sets and adjusted for chemotherapy. Squares indicate estimates for dose categories (0 Gy, 1 to $4 \mathrm{~Gy}, 5$ to $14 \mathrm{~Gy}, 15$ to $19 \mathrm{~Gy}, 20$ to $24 \mathrm{~Gy}, 25$ to $34 \mathrm{~Gy}$, and 35 to $45 \mathrm{~Gy}$ ) and are plotted at the median dose in each category (0 Gy, 3 Gy, 12 Gy, 18 Gy, 22 Gy, 28 Gy, and $38 \mathrm{~Gy})$. Vertical lines are $95 \% \mathrm{Cl}$. The regression line is the best-fitting dose-response relationship (RR, $1+0.07402 \times \mathrm{MHD} ; P<.001$ ), resulting in an excess relative risk (ERR) per Gy of $7.4 \%(95 \% \mathrm{Cl}, 3.3 \%$ to $14.8 \%)$.

h/wk of walking, cycling, or sports) had a considerably lower risk of developing CHD than did patients who were inactive $(<1 \mathrm{~h} / \mathrm{wk}$; RR, 0.52 ; 95\% CI, 0.32 to 0.83 ; Table 3 ). Also, a first-degree family history of CHD was an independent risk factor for CHD (RR, 2.87; 95\% CI, 1.41 to 5.88 ; Table 3 ).

\section{Interactions With Radiation}

We found no evidence for statistically significant modification of the effect of MHD on CHD risk by chemotherapy, sex, cardiovascular disease risk factors, and recent smoking at HL diagnosis (Appendix Table A4). ERRs seemed to be highest in the lowest tertile of age at $\mathrm{HL}$ diagnosis $\left(\mathrm{ERR}_{<27.5 y e a r s}, 20.0 \% / \mathrm{Gy} ; 95 \% \mathrm{CI}, 5.4 \%\right.$ to $70.5 \%)$ and decreased for the middle $\left(\mathrm{ERR}_{27.5-36.4 y e a r s}, 8.8 \% / \mathrm{Gy}\right.$; $95 \% \mathrm{CI}, 2.6 \%$ to $22.9 \%)$ and third tertile $\left(\mathrm{ERR}_{36.5-50.9 y e a r s}, 4.2 \% / \mathrm{Gy}\right.$; $95 \%$ CI, $0.6 \%$ to $11.1 \%$ ), although this difference was not statistically significant $\left(P_{\text {interaction }}=.149\right)$. Nevertheless, due to the lower background risk in patients treated at a young age, this higher relative risk did not materialize in a higher cumulative incidence at similar followup intervals after treatment (Fig 3).

\section{DISCUSSION}

To our knowledge, this study shows for the first time a linear doseresponse relationship for $\mathrm{MHD}$ and the risk of $\mathrm{CHD}$ in 5-year survivors of HL. The overall risk of CHD increased by $7.4 \%$ per Gy (95\% CI, 3.3\% to $14.8 \%$ ), resulting in a 2.5 -fold increased risk at a MHD of $20 \mathrm{~Gy}$. ERRs seemed to decrease with older age at treatment $\left(\mathrm{ERR}_{<27.5 \text { years }}, 20.0 \% / \mathrm{Gy} ; \mathrm{ERR}_{27.5-36.4 \text { years }}, 8.8 \% / \mathrm{Gy} ; \mathrm{ERR}_{36.5-50.9 y e a r s}\right.$, $4.2 \% / G y)$. Although other studies in childhood cancer and breast cancer survivors $^{10-12,22}$ also showed increased risks with higher radiation exposure of the heart, to our knowledge, our study is the first one with sufficient data to estimate the shape of the doseresponse curve for CHD among adolescent and adult HL survivors.

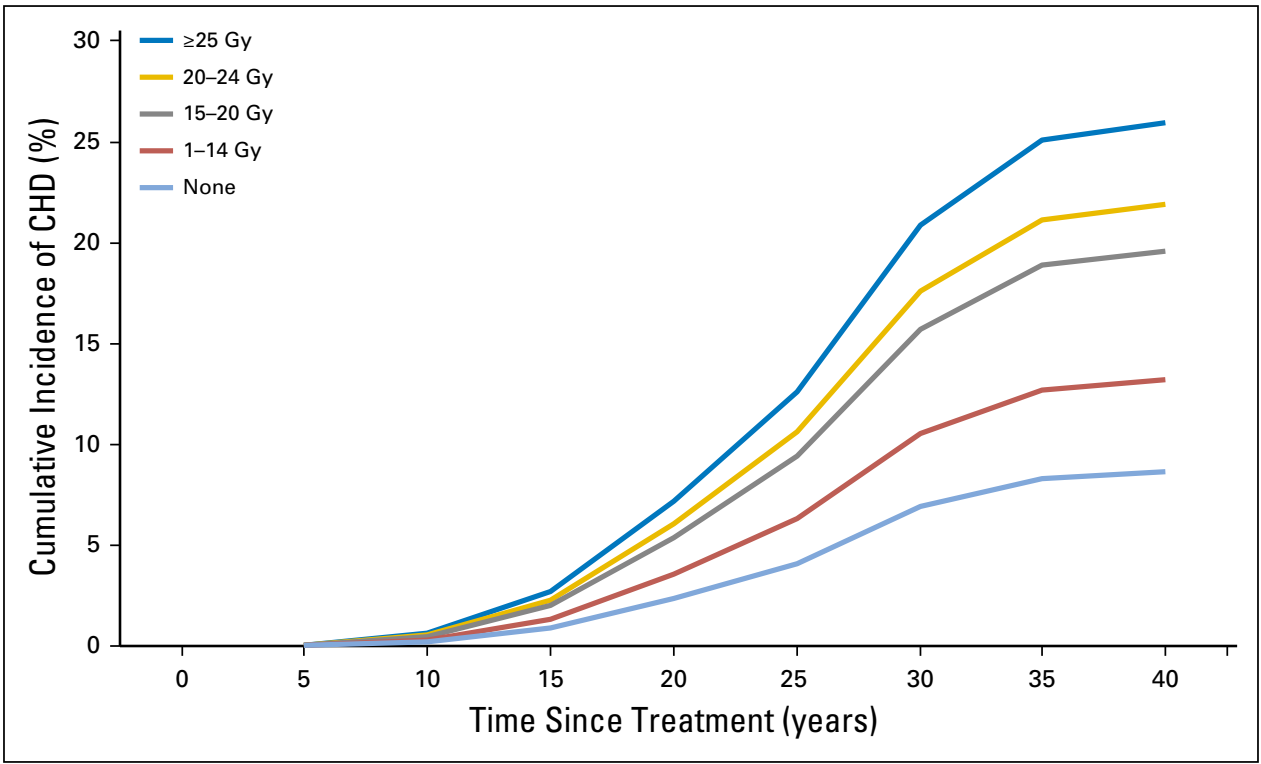

Fig 2. Cumulative incidence per category of mean heart dose (MHD). Cumulative risks of coronary heart disease (CHD) as first cardiac event among 5-year survivors of Hodgkin lymphoma $(\mathrm{HL})$ by time since initial $\mathrm{HL}$ treatment for categories of MHD (Gy). Cumulative risks were calculated with other heart disease or death as a competing risk. 


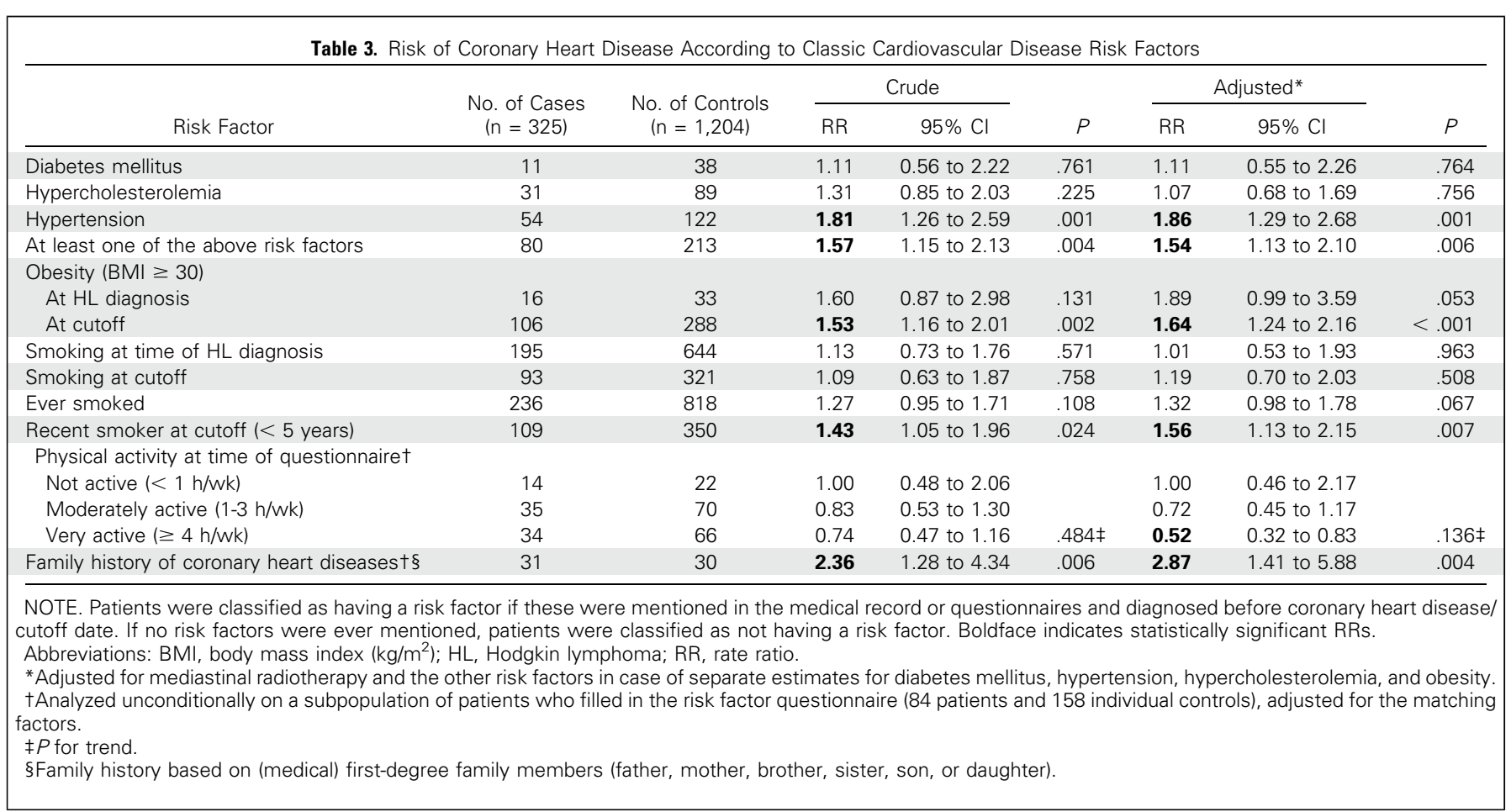

We previously studied the dose-response relationship for valvular heart disease risk after $\mathrm{HL}$ and observed an upward curvature with an ERR of 2.5\% per Gy for doses less than 30 Gy and $11.2 \%$ for doses of 36 to $40 \mathrm{~Gy}^{23}$ Because the mechanisms underlying the different types of heart damage after radiation remain unclear, a different pathogenesis may underlie the shape of the dose-response curve for valvular heart disease. Furthermore, uncertainties in assessment of dose to relevant target structures may add to the difference in findings.

Our results are consistent with the results of Darby et al, ${ }^{10}$ who also observed a linear dose-response relationship for the risk of major coronary events after radiotherapy for breast cancer. For the patients most comparable with the patients in Darby's article (ie, those treated between 36 and 50 years of age), however, we found an ERR of $4.2 \% / G y$, whereas Darby et $\mathrm{al}^{10}$ reported an ERR of 7.4\%/Gy. Because the confidence intervals of the ERRs in both studies overlap, it is likely that uncertainties in both data sets partially explain the difference in the magnitude of the ERRs. Our study and Darby's study also differed in terms of study population. Our study included both men and women, patients who were not irradiated, and patients who generally received a higher MHD. Furthermore, although breast cancer survivors frequently received a high dose to a small volume of the heart, HL survivors treated in the past generally received a relatively lower, more homogenous dose to a larger cardiac volume. ${ }^{24,25}$

Although a previous study ${ }^{12}$ only showed increased risks of CHD after a MHD exceeding $15 \mathrm{~Gy}$, other studies, ${ }^{10,26}$ including ours, indicate that there is no threshold dose. In future patients, clinicians should carefully weigh the benefits of reducing the MHD against potential risks of higher doses to other organs (ie, lungs and breasts in young females). Importantly, improved radiation policies, including reduction of radiation fields and breath-holding techniques, lead to MHDs of only 4 to $8 \mathrm{~Gy} .^{25,27,28}$
Unfortunately, we were unable to clearly separate the effect of irradiated heart volume from the effects of MHD due to collinearity of the MHD and the \%CVWF. However, the variation in irradiated heart volume in our population was limited, both in the total population as well as in specific categories of MHD (data not shown). The variation that occurs in traditional mantle-field irradiation mainly applies to variation in the irradiated volume of the apex, whereas the left main artery generally lies within the radiation field. There remains a gap in knowledge with respect to the role of irradiated heart volume, which should be studied in more depth to fully appreciate the consequences of irradiating a large part of the heart with a lower dose versus irradiating a smaller part of the heart with a high dose.

Neither chemotherapy in general nor specific chemotherapeutic agents were associated with CHD risk. Previously, anthracycline-containing chemotherapy has been associated with heart failure and, recently, with valvular heart disease, ${ }^{2,5,7,29}$ but not with CHD. Swerdlow et $\mathrm{al}^{30}$ previously observed an association between anthracycline- and vincristine-containing chemotherapy and the risk of death from myocardial infarction. We could not confirm these results.

In this study, we showed that hypertension, obesity, and recent smoking are independent risk factors for the development of CHD in HL survivors. Similar results have been published previously for childhood cancer survivors by Armstrong et al, who showed that survivors with one or more risk factors had a higher risk of developing major cardiac events compared with those without risk factors. ${ }^{31}$ Myrehaug et $\mathrm{al}^{5}$ found that having risk factors such as diabetes or a history of smoking were predictive for cardiac hospitalization in adult HL survivors. Because of the design of our study (case-control rather than prospective follow-up), we could not adequately examine the temporal relation between cardiovascular risk factors and development of CHD. However, our 

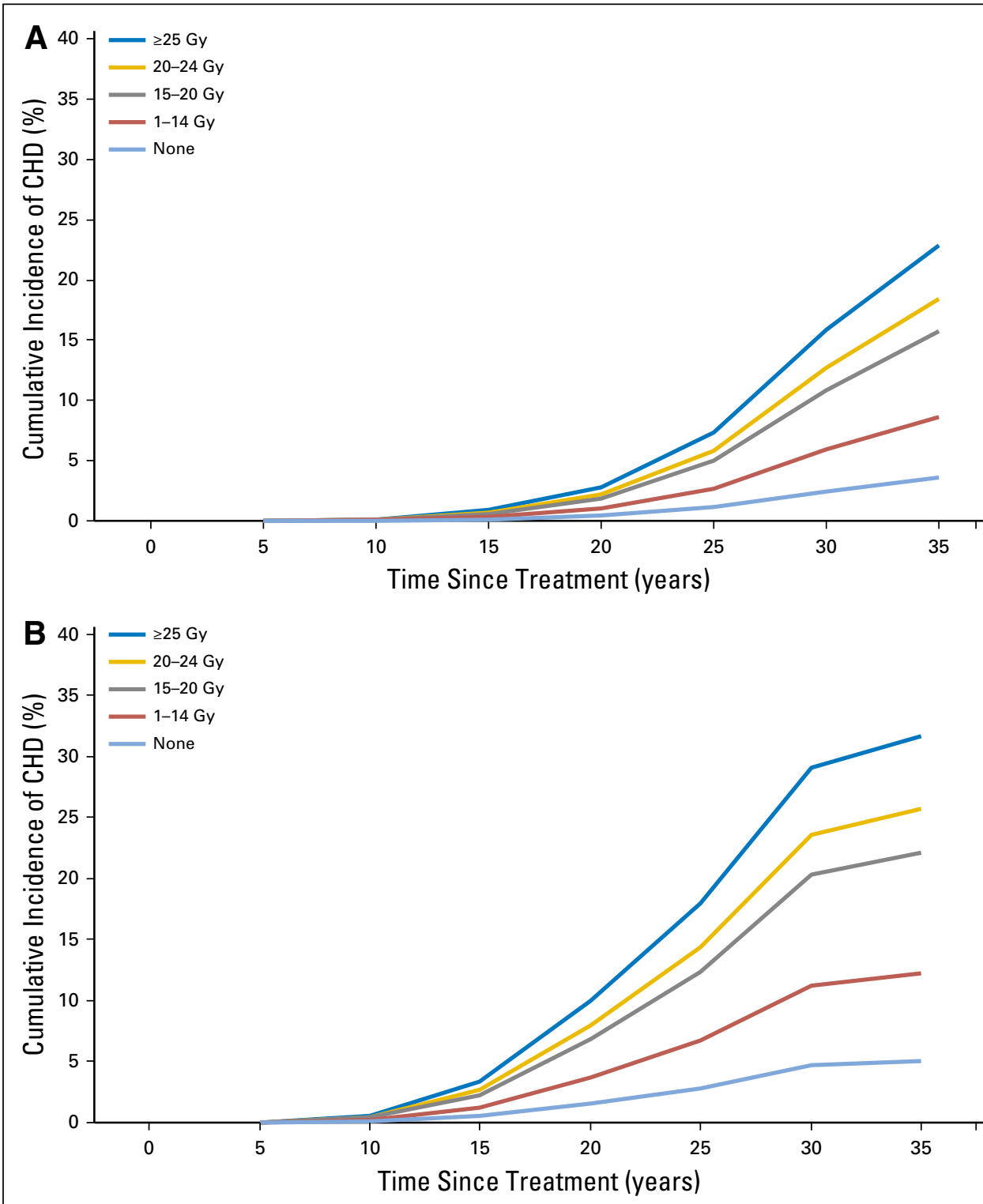

Fig 3. Cumulative incidence for different ages at the time of Hodgkin lymphoma $(\mathrm{HL})$ treatment. Cumulative risks of coronary heart disease (CHD) as first cardiac event among 5-year survivors of HL by time since initial HL treatment for categories of mean heart dose (Gy). Cumulative risks were calculated with other heart disease or death as a competing risk. (A) Cumulative incidence of $\mathrm{CHD}$ in $\mathrm{HL}$ survivors treated before age 27.5 years. (B) Cumulative incidence of $\mathrm{CHD}$ in $\mathrm{HL}$ survivors treated between ages 27.5 and 36.4 years. (C) Cumulative incidence of $\mathrm{CHD}$ in $\mathrm{HL}$ survivors treated between ages 36.5 and 50.9 years.

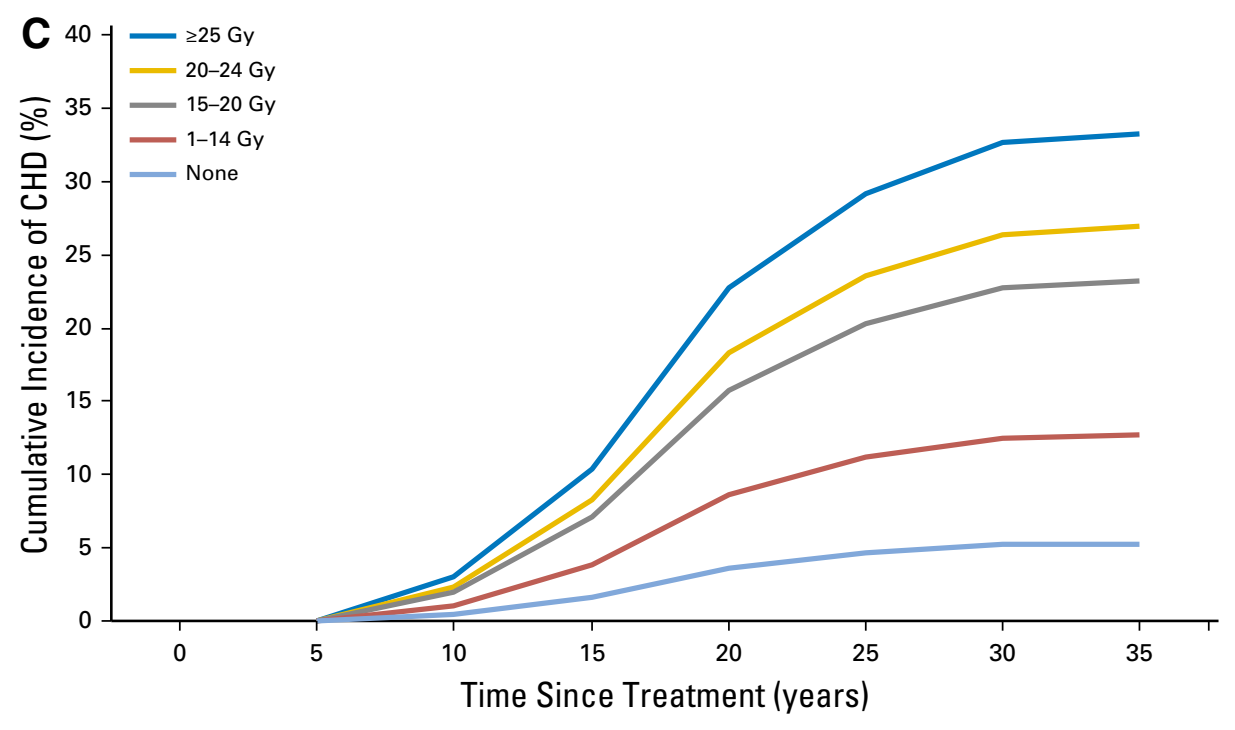


analyses, excluding risk factor information obtained around CHD diagnosis or corresponding cutoff date for controls, show that hypertension is an important risk factor for CHD. Additional analyses also including risk factors diagnosed around the time of CHD diagnosis or corresponding cutoff date showed that not only hypertension, but also hypercholesterolemia and diabetes are associated with an increased risk of CHD, but this observation may result from rigorous assessment of $\mathrm{CHD}$ risk factors at $\mathrm{CHD}$ diagnosis in cases and not in controls.

To our knowledge, we are the first to show that higher current physical activity levels may decrease CHD risk in adult HL survivors. Jones et $\mathrm{al}^{32}$ recently found a lower risk of treatmentrelated cardiac events in childhood cancer survivors who reported 9 metabolic equivalent-hours per week ${ }^{-1}$ or more, which is equivalent to approximately 2 to 2.5 hours of cycling or walking, or 1 to 1.5 hours of jogging or running. In this observational study, we could not determine whether the association with CHD was due to a causal effect of exercise or to reverse causation, in which the development of cardiac problems causes individuals to reduce the amount of exercise they perform. A randomized intervention trial is needed to provide more insight into the effects of physical activity on CHD risk in the HL population. Nevertheless, our findings regarding both exercise and cardiac risk factors, in combination with previous evidence regarding cardiac risk factors, underline the importance of risk factor control and maintenance or adoption of a healthy lifestyle after HL treatment.

We only included patients who developed CHD as their first cardiac event to evaluate the direct effect of HL treatment on CHD risk and to avoid confusion with secondary consequences of (treatment of) other heart diseases. In our recent cohort analysis, ${ }^{7}$ we did not find different associations between mediastinal radiotherapy and first CHD risk versus any CHD risk.

The use of MHD on the basis of the cardiac volume within the radiation fields might be considered a limitation compared with more advanced dosimetry techniques, such as the use of substitute CT data sets ${ }^{23}$ or matched deformable heart models. ${ }^{33}$ However, the current method has been shown to be accurate and has practical advantages. ${ }^{19}$ Compared with CT-based dosimetry, our method is less time-consuming and no expert knowledge is needed. More importantly, individual size and shape of the heart are taken into account, whereas other dosimetry methods used in retrospective studies on patients treated before the era of CT-based radiotherapy planning generally use one or two standard anatomic patients.

Unfortunately, our dosimetry method does not enable estimation of the radiation dose to the coronary arteries. However, Darby et $\mathrm{al}^{10}$ did estimate the radiation dose to the left anterior descending coronary artery, but found the MHD to be a better predictor of the rate of major coronary events than the mean dose to the left anterior descending artery, as the dose to the coronary arteries was an uncertain measure. The benefits of the currently applied method therefore outweigh the lack of a dose to specific substructures, especially because the location of the coronary event was often unknown for our cases.

In conclusion, mean radiation dose to the heart is an important risk factor for the development of CHD in HL survivors. To our knowledge, we are the first to show a linear radiation doseresponse relationship for CHD in HL survivors. This knowledge may help clinicians to predict the risk of CHD in HL patients treated today, as well as in survivors, and will assist in defining appropriate follow-up care for HL survivors. Furthermore, clinicians and patients should be aware of the importance of controlling general cardiovascular disease risk factors and maintaining a healthy lifestyle to reduce CHD risk.

\section{AUTHORS' DISCLOSURES OF POTENTIAL CONFLICTS} OF INTEREST

Disclosures provided by the authors are available with this article at www.jco.org

\section{AUTHOR CONTRIBUTIONS}

Conception and design: Frederika A. van Nimwegen, Michael Schaapveld, David J. Cutter, Sarah C. Darby, Berthe M.P. Aleman, Flora E. van Leeuwen Provision of study materials or patients: Cècile P.M. Janus, Augustinus D.G. Krol, Judith Roesink, Berthe M.P. Aleman

Financial support: Flora E. van Leeuwen

Collection and assembly of data: Frederika A. van Nimwegen, Cècile P.M. Janus, Augustinus D.G. Krol, Karen Kooijman, Judith Roesink, Richard van der Maazen

Data analysis and interpretation: Frederika A. van Nimwegen, Michael Schaapveld, Michael Hauptmann, Berthe M.P. Aleman, Flora E. van Leeuwen

Manuscript writing: All authors

Final approval of manuscript: All authors

\section{REFERENCES}

1. IKNL: Dutch cancer figures. 2012; http://www. cijfersoverkanker.nl

2. Aleman $B M P$, van den Belt-Dusebout $A W, D e$ Bruin $\mathrm{ML}$, et al: Late cardiotoxicity after treatment for Hodgkin lymphoma. Blood 109:1878-1886, 2007

3. Galper SL, Yu JB, Mauch PM, et al: Clinically significant cardiac disease in patients with Hodgkin lymphoma treated with mediastinal irradiation. Blood 117:412-418, 2011

4. Hull MC, Morris CG, Pepine CJ, et al: Valvular dysfunction and carotid, subclavian, and coronary artery disease in survivors of Hodgkin lymphoma treated with radiation therapy. JAMA 290:2831-2837, 2003
5. Myrehaug S, Pintilie M, Tsang R, et al: Cardiac morbidity following modern treatment for Hodgkin lymphoma: Supra-additive cardiotoxicity of doxorubicin and radiation therapy. Leuk Lymphoma 49 1486-1493, 2008

6. $\mathrm{Ng} A K$ : Review of the cardiac long-term effects of therapy for Hodgkin lymphoma. $\mathrm{Br} J$ Haematol 154:23-31, 2011

7. van Nimwegen FA, Schaapveld M, Janus CPM, et al: Cardiovascular disease after Hodgkin lymphoma treatment: 40-year disease risk. JAMA Intern Med 175:1007-1017, 2015

8. Raemaekers JM, André MP, Federico M, et al: Omitting radiotherapy in early positron emission tomography-negative stage $1 / /$ l Hodgkin lymphoma is associated with an increased risk of early relapse:
Clinical results of the preplanned interim analysis of the randomized EORTC/LYSA/FIL H10 trial. J Clin Oncol 32:1188-1194, 2014

9. Specht L, Yahalom J, Illidge $T$, et al: ILROG: Modern radiation therapy for Hodgkin lymphoma: Field and dose guidelines from the international lymphoma radiation oncology group (ILROG). Int J Radiat Oncol Biol Phys 89:854-862, 2014

10. Darby SC, Ewertz M, McGale P, et al: Risk of ischemic heart disease in women after radiotherapy for breast cancer. N Engl J Med 368:987-998, 2013

11. Schellong G, Riepenhausen $M$, Bruch $C$, et al: Late valvular and other cardiac diseases after different doses of mediastinal radiotherapy for Hodgkin disease in children and adolescents: Report from the longitudinal GPOH follow-up project of the German-Austrian 
DAL-HD studies. Pediatr Blood Cancer 55:1145-1152, 2010

12. Mulrooney DA, Yeazel MW, Kawashima T, et al: Cardiac outcomes in a cohort of adult survivors of childhood and adolescent cancer: Retrospective analysis of the Childhood Cancer Survivor Study cohort. BMJ 339:b4606, 2009

13. Armstrong GT, Kawashima $T$, Leisenring $W$, et al: Aging and risk of severe, disabling, lifethreatening, and fatal events in the childhood cancer survivor study. J Clin Oncol 32:1218-1227, 2014

14. Aleman BMP, van den Belt-Dusebout AW, Klokman WJ, et al: Long-term cause-specific mortality of patients treated for Hodgkin's disease. J Clin Oncol 21:3431-3439, 2003

15. De Bruin ML, Dorresteijn LD, van't Veer MB, et al: Increased risk of stroke and transient ischemic attack in 5-year survivors of Hodgkin lymphoma. $\mathrm{J}$ Natl Cancer Inst 101:928-937, 2009

16. van Leeuwen FE, Klokman WJ, Hagenbeek A, et al: Second cancer risk following Hodgkin's disease: A 20-year follow-up study. J Clin Oncol 12: 312-325, 1994

17. van Leeuwen FE, Klokman WJ, Veer MB, et al: Long-term risk of second malignancy in survivors of Hodgkin's disease treated during adolescence or young adulthood. J Clin Oncol 18:487-497, 2000

18. National Cancer Institute: Common terminology criteria for adverse events (CTCAE) version 4.0. Bethesda, MD, National Institutes of Health, 2009
19. van Nimwegen FA, Cutter DJ, Schaapveld M, et al: Simple method to estimate mean heart dose from Hodgkin lymphoma radiation therapy according to simulation x-rays. Int J Radiat Oncol Biol Phys 92: 153-160, 2015

20. Joiner MC, Van der Kogel AJ: Basic Clinical Radiobiology (ed 4). London, UK, Hodder Arnold, 2009

21. Plummer $\mathrm{M}$ : Improved estimates of floating absolute risk. Stat Med 23:93-104, 2004

22. Tukenova M, Guibout $C$, Oberlin O, et al: Role of cancer treatment in long-term overall and cardiovascular mortality after childhood cancer. J Clin Oncol 28:1308-1315, 2010

23. Cutter DJ, Schaapveld M, Darby SC, et al: Risk of valvular heart disease after treatment for Hodgkin lymphoma. J Natl Cancer Inst 107:djv008, 2015

24. Maraldo MV, Brodin NP, Aznar MC, et al: Estimated risk of cardiovascular disease and secondary cancers with modern highly conformal radiotherapy for early-stage mediastinal Hodgkin lymphoma. Ann Oncol 24:2113-2118, 2013

25. Maraldo MV, Brodin NP, Vogelius IR, et al: Risk of developing cardiovascular disease after involved node radiotherapy versus mantle field for Hodgkin lymphoma. Int J Radiat Oncol Biol Phys 83:1232-1237, 2012

26. Darby SC, Cutter DJ, Boerma $M$, et al: Radiation-related heart disease: Current knowledge and future prospects. Int J Radiat Oncol Biol Phys 76: $656-665,2010$
27. Paumier A, Ghalibafian $M$, Gilmore J, et al: Dosimetric benefits of intensity-modulated radiotherapy combined with the deep-inspiration breath-hold technique in patients with mediastinal Hodgkin's lymphoma. Int J Radiat Oncol Biol Phys 82:1522-1527, 2012

28. Petersen PM, Aznar MC, Berthelsen AK, et al: Prospective phase II trial of image-guided radiotherapy in Hodgkin lymphoma: benefit of deep inspiration breath-hold. Acta Oncol 54:60-66, 2015

29. van der Pal HJ, van Dalen EC, van Delden E, et al: High risk of symptomatic cardiac events in childhood cancer survivors. J Clin Oncol 30:1429-1437, 2012

30. Swerdlow AJ, Higgins CD, Smith $P$, et al: Myocardial infarction mortality risk after treatment for Hodgkin disease: A collaborative British cohort study. J Natl Cancer Inst 99:206-214, 2007

31. Armstrong GT, Oeffinger $K C$, Chen $Y$, et al: Modifiable risk factors and major cardiac events among adult survivors of childhood cancer. J Clin Oncol 31:3673-3680, 2013

32. Jones LW, Liu Q, Armstrong GT, et al: Exercise and risk of major cardiovascular events in adult survivors of childhood hodgkin lymphoma: A report from the childhood cancer survivor study. J Clin Oncol 32:3643-3650, 2014

33. $\mathrm{Ng} \mathrm{A}$, Brock KK, Sharpe MB, et al: Individualized $3 D$ reconstruction of normal tissue dose for patients with long-term follow-up: a step toward understanding dose risk for late toxicity. Int J Radiat Oncol Biol Phys 84:e557-e563, 2012 
Radiation Dose-Response Relationship for Risk of Coronary Heart Disease in Survivors of Hodgkin Lymphoma

The following represents disclosure information provided by authors of this manuscript. All relationships are considered compensated. Relationships are self-held unless noted. I = Immediate Family Member, Inst = My Institution. Relationships may not relate to the subject matter of this manuscript. For more information about ASCO's conflict of interest policy, please refer to www.asco.org/rwc or jco.ascopubs.org/site/ifc.

Frederika A. van Nimwegen

No relationship to disclose

Michael Schaapveld

No relationship to disclose

David J. Cutter

No relationship to disclose

Cècile P.M. Janus

No relationship to disclose

Augustinus D.G. Krol

No relationship to disclose

Michael Hauptmann

No relationship to disclose

\section{Karen Kooijman}

No relationship to disclose

Judith Roesink

No relationship to disclose

Richard van der Maazen

No relationship to disclose

\section{Sarah C. Darby}

No relationship to disclose

Berthe M.P. Aleman

No relationship to disclose

Flora E. van Leeuwen

No relationship to disclose 


\section{Acknowledgments}

We are grateful for all patients who were willing to participate in this study. We thank Saskia Pelders, Merian van Wouwe, Sandra Fase, Kim Kersten, Esther Janssen, Miranda Gerritsma, and Maaike van den Berg for their contributions to the collection of the data.

\section{Appendix}

\section{Grading Criteria for Coronary Heart Disease}

The conditions are graded (if possible, from the available information) according to the following criteria, adapted from the Common Terminology Criteria for Adverse Events.

Ischemic or coronary heart disease (angina pectoris and myocardial infarction):

- Grade 1: Records do not confirm the diagnosis of coronary artery disease. This group includes patients with a clinical diagnosis of angina pectoris but no other supporting information.

- Grade 2: Coronary artery disease confirmed by angiogram (but no acute myocardial infarction or revascularization). Probable coronary artery disease as evidenced by ischemic ECG changes (transient ST-segment depression and or T-wave flattening/inversion), imaging studies (eg, positive stress test), or other indirect evidence (eg, letters from cardiologists to general practitioners and drug treatment).

- Grade 3: Evidence of nonfatal acute myocardial infarction, such as ECG, laboratory, or imaging report (angiogram, echocardiogram, multigated acquisition). The patient is hemodynamically stable.

- Grade 4: The same as grade 3, but hemodynamically unstable or with life-threatening consequences (eg, severe hypotension, heart failure, or ventricular fibrillation requiring emergency resuscitation or inotropic/balloon pump support). Coronary revascularization (coronary artery bypass grafting or angioplasty/stenting).

\section{Dosimetry Method}

We outlined the cardiac contour on the Hodgkin lymphoma simulation radiographs. The percentage cardiac contour within the field (\%CCWF) was estimated by dividing the surface of the cardiac contour within the field by the surface of the total cardiac contour, multiplied by 100 . The $\%$ CCWF was multiplied by a correction factor of 1.12 to obtain the $\%$ CCWF. ${ }^{19}$ The prescribed radiation dose to the mediastinum was converted to the equivalent dose in 2-Gy fractions, and the alpha-beta ratio was assumed to be 2 Gy for late cardiac effects. ${ }^{26}$ The equivalent dose in 2-Gy was multiplied by the \%CCWF to obtain the mean heart dose (MHD) in Gy. The MHD was multiplied by 1.10 or 1.05 for patients who received para-aortic radiotherapy with or without splenic radiotherapy, respectively. ${ }^{19}$ Patients who received para-aortic radiotherapy with or without splenic radiotherapy, but no mediastinal radiotherapy, were assigned a MHD of 4 and $2 \mathrm{~Gy}$, respectively, based on previous dosimetric findings. ${ }^{19}$

\begin{tabular}{|c|c|c|c|c|c|c|}
\hline & No. with AP & $\%$ & No. with Ml & $\%$ & $\begin{array}{l}\text { Total } \\
\text { No. }\end{array}$ & $\%$ \\
\hline Total & 140 & 100 & 185 & 100 & 325 & 100 \\
\hline \multicolumn{7}{|l|}{ Grade } \\
\hline 2 & $140^{*}$ & 100 & - & & 140 & 43.1 \\
\hline 3 & - & & 118 & 63.8 & 118 & 36.3 \\
\hline 4 & - & & 36 & 19.5 & 36 & 11.1 \\
\hline 5 & - & & 31 & 16.7 & 31 & 9.5 \\
\hline \multicolumn{7}{|l|}{ Treatment† } \\
\hline Drug therapy & 28 & 20.0 & 34 & 18.4 & 62 & 19.1 \\
\hline $\mathrm{PCl}$ & 41 & 29.3 & 48 & 25.9 & 89 & 27.4 \\
\hline CABG & 54 & 38.6 & 13 & 7.0 & 67 & 20.6 \\
\hline None & - & & $14 \ddagger$ & 7.6 & 14 & 4.3 \\
\hline Unknown & 17 & 12.1 & $76 \S$ & 41.1 & 94 & 28.9 \\
\hline \multicolumn{7}{|l|}{ Death } \\
\hline Deceased at end of follow-up & 56 & 40.0 & 113 & 61.1 & 169 & 52.0 \\
\hline Death due to cardiac cause & 16 & 28.6 & 56 & 49.5 & 72 & 42.6 \\
\hline Death due to other malignancy & 11 & 19.6 & 22 & 19.5 & 33 & 19.5 \\
\hline Death due to other causes & 7 & 12.5 & 15 & 13.3 & 22 & 13.0 \\
\hline Unknown cause of death & 22 & 39.3 & 20 & 17.7 & 42 & 24.9 \\
\hline
\end{tabular}




\begin{tabular}{|c|c|c|c|c|c|c|c|c|}
\hline \multirow[b]{2}{*}{ Treatment Factor } & \multirow{2}{*}{$\begin{array}{l}\text { No. of Cases } \\
\text { (Total }=220 \text { ) }\end{array}$} & \multirow{2}{*}{$\begin{array}{l}\text { No. of Controls } \\
\text { (Total }=836)\end{array}$} & \multicolumn{2}{|c|}{ Crude } & \multirow[b]{2}{*}{$P$} & \multicolumn{2}{|c|}{ Adjusted* } & \multirow[b]{2}{*}{$P$} \\
\hline & & & $\mathrm{RR}$ & $95 \% \mathrm{Cl}$ & & $\mathrm{RR}$ & $95 \% \mathrm{Cl}$ & \\
\hline \multicolumn{9}{|l|}{ Mean heart dose, Gy } \\
\hline 0 & 17 & 160 & 1.00 & 0.60 to 1.66 & & 1.00 & 0.60 to 1.68 & \\
\hline $1-4$ & 12 & 93 & 1.19 & 0.65 to 2.19 & & 1.13 & 0.62 to 2.09 & \\
\hline $5-14$ & 16 & 64 & 2.52 & 1.45 to 4.37 & & 2.48 & 1.43 to 4.32 & \\
\hline $15-19$ & 39 & 130 & 2.89 & 2.02 to 4.15 & & 2.80 & 1.95 to 4.02 & \\
\hline $20-24$ & 65 & 186 & 3.49 & 2.63 to 4.62 & & 3.32 & 2.51 to 4.40 & \\
\hline $25-34$ & 67 & 183 & 3.85 & 2.87 to 5.15 & & 3.63 & 2.69 to 4.89 & \\
\hline $35-45$ & 4 & 20 & 2.29 & 0.77 to 6.79 & $<.001 \dagger$ & 2.20 & 0.74 to 6.51 & $<.001 \dagger$ \\
\hline \multicolumn{9}{|c|}{$\begin{array}{l}\text { NOTE. Unimputed data. Unconditional analyses were performed and therefore were adjusted for matching factors (age at Hodgkin lymphoma diagnosis, sex, and year } \\
\text { of Hodgkin lymphoma diagnosis). Included only patients for whom a mean heart dose could be calculated, based on available prescribed dose and simulation radiographs } \\
\text { (220 cases and } 836 \text { controls). Boldface indicates significanlty increased RRs. } \\
\text { Abbreviations: RR, rate ratio. } \\
\text { *Mean heart dose was adjusted for chemotherapy. } \\
\text { †P for trend. }\end{array}$} \\
\hline
\end{tabular}

\begin{tabular}{|c|c|c|c|c|c|c|c|c|}
\hline \multirow[b]{2}{*}{ Risk factor } & \multirow{2}{*}{$\begin{array}{l}\text { No. of Cases } \\
\text { (Total = 325) }\end{array}$} & \multirow{2}{*}{$\begin{array}{l}\text { No. of Controls } \\
\text { (Total }=1,204)\end{array}$} & \multicolumn{2}{|c|}{ Crude } & \multirow[b]{2}{*}{$P$} & \multicolumn{2}{|c|}{ Adjusted* } & \multirow[b]{2}{*}{$P$} \\
\hline & & & $\mathrm{RR}$ & $95 \% \mathrm{Cl}$ & & $\mathrm{RR}$ & $95 \% \mathrm{Cl}$ & \\
\hline Diabetes mellitus & 66 & 149 & 1.92 & 1.38 to 2.67 & $<.001$ & 1.98 & 1.41 to 2.77 & $<.001$ \\
\hline Hypercholesterolemia & 154 & 363 & 2.17 & 1.67 to 2.82 & $<.001$ & 2.08 & 1.60 to 2.72 & $<.001$ \\
\hline Hypertension & 139 & 407 & 1.47 & 1.15 to 1.89 & .003 & 1.52 & 1.18 to 1.96 & .001 \\
\hline At least one of the above risk factors & 261 & 769 & 2.36 & 1.74 to 3.22 & $<.001$ & 2.51 & 1.84 to 3.44 & $<.001$ \\
\hline
\end{tabular}

\begin{tabular}{|lll|}
\hline & Table A4. Excess Relative Risks per Gray Mean Heart Dose for Relevant Subgroups \\
\hline & ERR (\%) & \multicolumn{1}{c|}{$95 \% \mathrm{Cl}$} \\
\hline Men & 7.4 & 3.0 to 15.8 \\
Women & 7.2 & 0.7 to 34.4 \\
Follow-up time of 5-14 years & 6.4 & 1.2 to 18.9 \\
Follow-up time of 15-29 years & 8.1 & 2.7 to 20.6 \\
Follow-up time of 30-43 years & 7.8 & -0.7 to 73.5 \\
Treated before age 27.5 & 20.0 & 5.4 to 70.5 \\
Treated between ages 27.5 and 36.4 & 8.8 & 2.6 to 22.9 \\
Treated between ages 36.5 and 50.9 & 4.2 & 0.6 to 11.1 \\
No chemotherapy & 8.6 & 3.9 to 16.9 \\
Chemotherapy & 7.1 & 3.0 to 14.4 \\
No classic risk factors & 7.0 & 2.8 to 15.1 \\
$\geq 1$ classic risk factor & 9.7 & 1.3 to 44.5 \\
Non-recent smoker & 14.8 & -5.3 to 53.4 \\
Recent smoker & 8.0 & -31.7 to $24.4 \%$ \\
\hline
\end{tabular}

Abbreviations: ERR, excess relative risk. 